\title{
ENTRE A AUTORIA E A REDENÇÃO: ABORDAGENS CRÍTICAS ACERCA DE NIKOS KAZANTZAKIS
}

\begin{abstract}
Carolina Donega Bernardes: doutoranda em Letras (área de concentração em Teoria da Literatura) pela Universidade Estadual Paulista (UNESP), campus de São José do Rio Preto. Sua pesquisa, com auxílio FAPESP, analisa a Odisséia de Kazantzakis como épico na modernidade e sua relação com a obra de Homero.

E-mail: biabeca@gmail.com
\end{abstract}

Resumo: Parcamente conhecido no cenário brasileiro, o autor grego moderno Nikos Kazantzakis tem sido amplamente estudado em âmbito mundial. No entanto, por mais que as pesquisas sejam numerosas, é importante notar que sofrem a tendência problemática de associar autor e obra, em detrimento da segunda. O presente artigo procura refletir a respeito das razões que levam a crítica canônica de Nikos Kazantzakis a preocupar-se muito mais em deslindar a personalidade do autor, vinculandoo aos seus personagens, do que com a própria obra, à qual se dirige, frequentemente, como objeto de elucidação do projeto estético e filosófico do autor. Pretendemos demonstrar, ainda, que o tratamento dispensado a Kazantzakis e sua obra não se deve somente ao posicionamento da crítica, mas principalmente revela uma tendência encorajada pelo próprio autor, que encontra na literatura a ação metapolítica para sua redenção pessoal, assim como o modo de colaborar para a salvação coletiva em tempos de crise.

\begin{abstract}
Resumen: Poco conocido en el escenario brasileño, el autor griego moderno Nikos Kazantzakis ha sido ampliamente estudiado en todo el mundo. Sin embargo, mismo que las investigaciones sean numerosas, es importante señalar que sufren la preocupante tendencia de vincular el autor y la obra, en detrimento de este último. Este artículo pretende reflexionar sobre las razones que llevan la crítica canónica de Nikos Kazantzakis a preocuparse mucho más por desentrañar la personalidad del autor, y menos con su propia obra, a la cual se dirige, a menudo, como objeto de elucidación del proyecto estético y filosófico del autor. Nos proponemos demostrar, además, que el tratamiento sobre Kazantzakis y su trabajo no es sólo debido a la posición de la crítica, sino más bien muestra una tendencia alentada por el autor, que encuentra en la literatura la acción meta-política para su redención personal, así como para trabajar en pro de la salvación colectiva en tiempos de crisis.
\end{abstract}

Toda minh'alma é um grito e todo o meu trabalho o comentário sobre esse grito. (Kazantzakis. Testamento para el Greco)

Inquietude é a palavra de ordem para o percurso que ora encetamos. Um percurso que não só acompanha o novo périplo de Odisseu em sua sede pelo "mais além”, mas começa pela tentativa de desvelar o móbil do itinerário incessante do escritor grego Nikos Kazantzakis (1883-1957) e o fermento filosófico que o intensificou e direcionou.

Homem de contradições, ateu, comunista, dissidente, desterrado, desinteressado dos problemas socais: assim Kazantzakis era conhecido na Grécia de sua época ${ }^{1}$. Homem de aspecto sereno, resplandecendo confiança e harmonia: assim era visto pelos amigos. Homem de conflitos, cretense, profeta, combatente incansável, que jamais aceitou o repouso de uma conquista: assim ele mesmo se reconhecia. Para os críticos, Kazantzakis é visto, ainda, como um homem apaixonado, filósofo, um herói aos moldes de Odisseu, não obstante torturado pelas inquietações. A diversidade de adjetivos para 
exprimir o gênio do autor notadamente atesta uma personalidade que tem suscitado polêmicas, reações extremadas de admiração ou repulsa, confundidas todas elas com seu trabalho literário.

$\mathrm{Na}$ verdade, mais importante do que constatar o conflito permanente nas avaliações do autor realizadas por diferentes grupos, é perceber (e discutir) que o autor tem sido analisado pela grande crítica e pelos leitores comuns como entidade real e como atestador da filosofia subjacente na obra. Não é uma tendência isolada, mas as atenções de todos os pesquisadores se voltam ao sem-número de $\operatorname{cartas}^{2}$ que revelam o homem e iluminam aspectos do processo criativo que resultou na produção literária, de suas crenças filosóficas, de sua busca angustiada pela ascensão e pela liberdade, de sua identificação com personalidades da história humana. Alguns foram amigos próximos, como P. Prevelakis, Kimon Friar e Eleni Kazantzakis (a esposa), e claramente traçam um perfil psicológico do autor referendado pelas cartas, outros se mostram mais interessados nas experiências pessoais do escritor, mais em sua trajetória real do que na leitura crítica de sua obra. Roberto Quiroz Pizarro reitera a tendência crítica:

Uma maneira de continuar a busca relacionada com o espírito criador de Kazantzakis, mais além da criação literária propriamente tal, é de dar espaço aos escritos pessoais que se referem mais ao homem. Contudo, há que destacar que um livre pensador como foi Kazantzakis não deixa de sê-lo porque mude do plano da literatura para o do estreito círculo das cartas escritas a seus contemporâneos. Melhor se aprecia uma continuidade de fundo, uma espontaneidade para projetar suas mesmas preocupações e tentativas intelectuais. Nas cartas e em outros escritos, apreciamos seus imponderáveis desejos e paixões de luta, ao redor de cuja tocha também se iluminam pensamentos e luzes de uma complexa cosmovisão ligada à sua obra e à sua vida. (PIZARRO, 2003, p. 335)

Essa tendência em processo alerta para um problema na avaliação da produção kazantzakiana: a obra seria apenas um veículo para se chegar ao autor, uma confirmação do projeto inicial reiteradamente divulgado. Por mais que esta mesma crítica afirme a grandiosidade dos textos de Kazantzakis, a hierarquia autor/obra mantém-se evidente, pois as atenções ao texto são meramente descritivas e se esmeram num conjunto de adjetivos valorativos que nada fazem além de elogiar a capacidade criativa daquele que o produziu, valores esses que justificam e alimentam a imagem do autor heróico, profético e inquieto. As palavras de Bidal-Baudier são uma pequena amostra de um discurso que se repete não só em Cómo el hombre se hace inmortal, como também no discurso da crítica canônica de Kazantzakis:

Para compreender o que torna tão excepcional a personalidade de Kazantzakis, mencionemos a graça de outro dom que os deuses reservam a seus eleitos: uma imaginação de visionário. Esta chama a atenção desde sua infância por seu poder de transfiguração do real: o jovem Nikos vive em plena lenda, se movimenta no meio dela e recria a cada instante; vê sereias; tenta lançar-se ao fundo de um poço para encontrar a cidade encantada; (...) Dirão que é privilégio da infância viver em um mundo imaginário. Dirão também que as recordações de infância evocadas por Kazantzakis até o fim de sua vida em Testamento para el Greco são recordações reconstituídas pelo velho escritor através dos leitmotiv que foram a obsessão de toda sua existência. Não 
creio. O poeta que compôs a maior epopéia dos tempos modernos e dono de uma potente visão poética que dificilmente se poderia consignar e encerrar em palavras, teve desde a infância, não duvidemos, o poder de ver a realidade maior, mais esplendorosa, mais conforme seus desejos secretos. Esta primeira visão do mundo - tão poderosa seguiu sendo inalterável para ele e é com idêntica paixão, nos disse, a mesma que tinha na infância, que contemplou em toda sua vida o céu estrelado ou o mar. (BAUDIER, 1987, p.29-30)

A busca pela apreensão da personalidade do autor, que teria sido constituída e reforçada por uma dádiva divina, revela uma crítica ainda presa aos ideais românticos. A crítica estaria em busca, portanto, do autor inspirado, gênio possuído e capaz de sentir "forças inconscientes se unirem a forças conscientes na produção da obra de arte" (MACHADO, 2006, p. 92), como aquele que tem acesso a uma revelação, a uma verdade reservada apenas aos eleitos, àqueles que detêm certa capacidade de decodificar em forma de arte a realidade sensível. Enquanto o ideal de gênio torna-se amplamente difundido no Romantismo e "passa a ser a capacidade sintética que universaliza e transubstancia, a arte se volve no modelo da atividade espiritual, compartindo, em sua essência, do caráter superior, profundo e íntimo da realidade eterna e absoluta, de que é a única via de acesso". (NUNES, 1993, p. 61-62) Somente a biografia e o estudo atento das confidências do autor são capazes de captar o poder visionário e profético que a obra parece conter.

Kazantzakis torna-se uma entidade sempre presente em sua obra, virtualmente atuante como personagem e criador de si mesmo. Isso significa que, pela crítica do gênio inspirado, a trajetória de seus personagens nada mais representaria do que o caminho para a transcendência, para a unidade almejada com as forças visíveis e as latentes do universo.

No entanto, a existência de tal crítica ainda na contemporaneidade pode ser avaliada em suas implicações e nas razões que possivelmente a incentivaram neste rumo. A primeira delas se relaciona com o próprio Kazantzakis, o maior fomentador do fascínio pela sua figura. Ao confundir suas ações com as de seus personagens, num processo de auto-identificação com a ficção, Kazantzakis projeta em seus personagens o percurso de ascensão que desejaria lograr. Assim como imprimiu à literatura as linhas de pensamento que compõem a trajetória de cada uma das figuras representadas, o próprio poeta procurou vivenciá-las na prática, atraindo a atenção para si como uma figura envolta pela mesma aura heróica que define seus personagens. Em Testamento para el Greco (publicação póstuma), o autor relata os passos decisivos de sua trajetória, desde a infância, romanceando algumas passagens, como ele mesmo declara. Assim, além da vasta produção epistolar, o autor deixa ao público um romance no qual ele assume o papel de herói, daquele que vive no plano real as experiências de Odisseu. No prólogo, Kazantzakis confidencia:

Os degraus decisivos para minha ascensão foram quatro. E cada um porta um nome sagrado: Cristo, Buda, Lênin, Odisseu. Esta jornada de sangue, de uma destas grandes almas à próxima, é pelo que lutarei em especificar neste itinerário, agora que o sol 
principia a se pôr. A jornada de um homem com o coração na boca, escalando a áspera e incômoda montanha de seu destino. Toda minh'alma é um grito e todo meu trabalho o comentário sobre este grito. (KAZANTZAKIS, s/d, p. 15)

A escrita pessoal de Kazantzakis revela a ânsia de alcançar, por meio da literatura, a concretização das teorias que envolvem homens históricos ou ficcionais que abriram caminho para a fundação de uma nova forma de avaliação do mundo e que lograram subjugar o ego e a matéria para percorrer um caminho de abnegação, luta e amor em favor da coletividade, guias da humanidade que, de algum modo, entregaram aos homens uma quimera, uma utopia ou uma nova religião. A correspondência e os relatos em primeira pessoa confidenciados em Testamento para el Greco $^{4}$ refletem a busca incansável de seguir os passos de grandes guias do espírito humano, como Jesus Cristo, Buda e Lênin, uma caminhada de elevação que se cumpre no plano da escrita, em oposição ao próprio movimento que esses homens representam.

A relação com personalidades do conhecimento humano (e aqui acrescentamos Bergson, Nietzsche, Zorba, São Francisco de Assis) ${ }^{5}$ não pode ser descrita como simples influência, mais do que isso, ela chega mesmo a se pautar em uma forte obsessão. Kazantzakis conjura esses "guias do espírito", pois neles identifica o modelo de vida exemplar, que, para o autor, estaria relacionado com um tipo de heroicidade pertinente ao mundo e época em que viveram. Apesar do afastamento temporal que comungam entre si e da disparidade das ideias que cultivaram (quase todas irreconciliáveis), esses modelos representavam para Kazantzakis um único e mesmo caminho: o esforço heróico, vital e visionário de superação do destino e dos valores arraigados. Não se vê simplesmente uma atração e absorção das idéias que cada um deles enforma, mas um fascínio pela trajetória pessoal que os leva ao que Kazantzakis chamava de "transmutação da carne em espírito", princípio vitalista de criação em meio ao mundo fenomênico e relativista.

Em busca desse princípio e reconhecendo na luta de seus guias o seu próprio combate, Kazantzakis assimila essas idéias - de maneira paradoxal, já que suas doutrinas não se podem conciliar - e se esforça (e aqui começa o seu próprio combate) por harmonizá-las. É com este intuito que revive, profundamente imerso, a trajetória dos guias maiores (Bergson, Cristo, Nietzsche, Buda, Lênin), cada um a seu tempo e por etapas sucessivas, como ele mesmo descreve em sua autobiografia. Verificamos, portanto, nesta fixação pela vida de personalidades importantes e reconhecidas a obsessão que terá gerado o fascínio de críticos e leitores pela sua própria figura; obsessão que o levará a intitular a maioria de suas tragédias com o nome próprio do personagem a quem reverencia ${ }^{6}$, assim como tornará central, solar, um personagem representativo de tais ideais em seus romances ${ }^{7}$ e na épica de Odisseu (referimo-nos à epopeia do autor Odisséia, de 1938), seu magno protótipo de herói.

A percepção de que diversos homens foram capazes de elevar-se acima das limitações de seu tempo torna a busca de Kazantzakis mais ferrenha e inquieta. Associando figuras heróicas com as doutrinas que sustentaram, o autor se empenha em um projeto de ascensão que inclui vida e obra, revelando interesse não pela realização 
estética em si, mas principalmente pela transformação pessoal e coletiva. Ao fundir a instância literária com a experiência humana, o projeto de "transmutação da matéria em espírito" vai além do ficcional e abarca as relações do autor-homem com Deus, com o outro, consigo mesmo e com a natureza. Deste modo, parece-nos evidente que Kazantzakis não distingue a trajetória de seus heróis da sua própria, autorizando e legitimando, portanto, a crítica da autoria intencional. Seria admissível, numa crítica biográfica corroborada pelo autor, a inclusão das confidências de Kazantzakis no conjunto da obra literária, pois chegaríamos aqui às indagações de Foucault sobre a noção de obra: "Como definir uma obra entre os milhões de vestígios deixados por alguém depois da morte?” (FOUCAULT, 1992, p.38). A definição de obra apresenta-se tão problemática quanto a definição do autor, querela histórica no âmbito da teoria literária.

Ao contrário de alimentarmos o debate em busca de uma definição, e principalmente assumir uma posição ou outra em relação à crítica de Kazantzakis, consideramos importante reavaliar determinadas conclusões e os conflitos provenientes das leituras que não preveem a significação da máxima amplitude do texto, composto por uma diversidade de fundo: a história, a filosofia, a biografia, o projeto estético elaborado pelo autor e a significação que se lhe dá pela leitura. Tal amplitude característica do texto literário nos leva a considerar a importância da leitura de todo material que possa oferecer recursos e suscitar reflexões que permitam a abertura das análises, incorporando os elementos de significação não previstos pelo autor e as tensões instauradas pela obra não consideradas pela crítica.

O problema, portanto, não está em considerar as cartas e confidências de Kazantzakis como textos válidos na interpretação, mas o aproveitamento que se faz delas, fortalecendo uma tendência que, se ficasse somente na apreensão de Kazantzakis como herói de seu próprio destino, não seria um ato comprometedor em si, mas, muito mais do que isso, é um movimento que leva ao descritivismo do texto literário, análise que traz como consequências a reprodução de passagens consideradas capitais para a confirmação do projeto estético do autor e a associação de personagens às suas experiências filosóficas, bem como a síntese do enredo e a reiteração da complexidade poética e narrativa, arrematando que os pontos mais obscuros do texto são mistérios insolúveis (provavelmente porque são lacunas às quais Kazantzakis não deixou comentário ou porque excedem seu projeto estético), como se houvesse uma mensagem cifrada e somente o conhecimento da intencionalidade e a experiência vivida pudessem decodificá-la e justificar sua presença no texto.

A segunda razão que talvez tenha incentivado a crítica a desenvolver avaliações atestadas pelo biografismo começa, a partir dessas reflexões, a se pronunciar. Não se trata mais da legitimação oferecida pelo autor, mas do relacionamento da crítica com seus objetivos e procedimento de análise, e principalmente a subordinação a uma construção de ordem psicológica: o mestre como salvador. Kazantzakis não é tãosomente a autoridade do texto, mas o homem tornado mestre, reverenciado não pela 
aura de gênio poético, comum no Romantismo, e sim pelo caminho de elevação que lhe rendeu, aos olhos alheios, a aura dos iluminados.

O que desperta o fascínio por Kazantzakis é o esforço empreendido contra toda sorte de conflitos em busca da superação de si, da redenção e da síntese das oposições. É neste aspecto que se revela o caráter de combatente incessante "para crescer, elevarse, para permitir a expansão da parte divina de si mesmo e permitir a Deus que se libere da matéria." (BAUDIER, 1987, p.61). O combate é a sua porção heroica, intimamente relacionada com a visão filosófica e vitalista que lhe serviu de base. Compreendendo doutrinas diversas, o sistema filosófico kazantzakiano estimulou a atribuição do título de pensador $^{8}$ que tem sido sustentada, ainda que tenha apenas se aproveitado (e absorvido) das idéias de filósofos reconhecidos e de conceitos já sedimentados para compor seu projeto pessoal.

Desse modo, como pensador e poeta, Kazantzakis apresenta-se aos leitores como figura de superação e positividade em meio ao que se tem denominado "crise do século XX". Amealhando o niilismo nietzschiano, a evolução criadora promulgada por Bergson e o conceito de "era transicional" proveniente de Oswald Spengler, Kazantzakis articula um processo vitalista de permanente reavaliação de conceitos e doutrinas cristalizados pela tradição, sinalizando a possibilidade de criação de si e do mundo e a descoberta de uma nova compreensão de Deus, no contexto modernista de descrença e falência da cultura ocidental. Esse caráter de imprimir positividade à negatividade do momento histórico é expandido para uma postura que o faz assumir o dever de redenção da coletividade. Neste aspecto, revela-se homem político, não no sentido de engajar-se ativamente pela transformação social, mas no sentido de instar o leitor ao círculo vitalista no qual estava inserido pela sua própria redenção.

Se muitos foram os conflitos de Kazantzakis, um deles se baseia exatamente na oposição entre ação e contemplação ${ }^{9}$, levando-o a profundos questionamentos quanto à atitude correta em relação ao seu tempo. O não-envolvimento de maneira ativa com partidos e movimentos políticos, apesar de sua fase nacionalista e do interesse marcante pelo comunismo, e a predisposição ao isolamento, à reclusão ascética e aos questionamentos de ordem religiosa autorizam a crítica engajada a considerar Kazantzakis desinteressado dos problemas de seu tempo, mais preocupado com a salvação pessoal. Peter Bien (2007, p.4) contesta a tendência, alertando para o fato de que a crítica falha ao não perceber que não há separação entre as duas instâncias, pois a salvação para Kazantzakis encontra-se no engajamento com a coletividade, que pode ser avaliado como político. Seu interesse dirigia-se à meta-política, rota indireta que, ao passar pelo social, leva à ascensão. Assim, não era a política que lhe interessava, mas as questões suscitadas por ela para alcançar algo mais importante: a liberdade.

Se o interesse de Kazantzakis não estava propriamente na política, seu modo de ação não se insere num campo de batalha ou nos gabinetes executivos; é na literatura que acreditará ter encontrado sua ferramenta de luta e o ponto de equilíbrio para a tensão ação/contemplação, pois, adquirindo finalidade, a escrita transcende o estético 
para assumir o poder de transformação do real, sem que para isso Kazantzakis precisasse abdicar de seu desejo de isolamento e retiro ascético.

Escrever poderia ter sido um jogo em outros tempos, em tempos de equilíbrio. Hoje é um grave dever. Seu objetivo não é o de entreter a mente com contos de fadas e fazer com que esqueça, mas o de proclamar um estado de mobilização a todas as forças luminosas que ainda sobrevivem na nossa época de transição e de apressar os homens a fazerem o máximo para ultrapassar o animal. (...) Quanto mais escrevia, mais sentia que ao escrever eu lutava, não pela beleza, mas pela redenção. Ao contrário de um escritor de verdade, eu não conseguia tirar nenhum prazer em criar uma frase enfeitada ou de combinar uma rima sonora; eu era um homem que lutava e que estava machucado, um homem que buscava a redenção. Queria ser liberto de minha própria escuridão interior e de transformá-la em luz, queria ser liberto dos terríveis ancestrais que rugiam em mim e transformá-los em seres humanos. E por isto eu invocava os grandes personagens que tinham, sucessivamente, passado pelas provações as mais elevadas e as mais difíceis... (KAZANTZAKIS, s/d, p.314)

Continuamente, o autor se refere em sua produção à crise do momento histórico e à necessidade de envolvimento para a redenção coletiva, o que confirma a hipótese de Bien, desautorizando as leituras que identificam no autor a alienação e desinteresse pelas questões éticas. A preocupação com a coletividade é obstinada ao ponto de figurar na centralidade de sua concepção filosófica, como expresso na obra de 1927 Ascese:

Somos todos um, somos todos uma essência em perigo. Uma alma que decline do outro lado do mundo arrasta para a ruína também a nossa alma. Um cérebro que se imbecilize do outro lado do mundo enche nossas têmporas de trevas. / Porque alguém luta nos confins do céu e da terra: o Um. E se perder-se, a responsabilidade será nossa. Se perder-se, nós nos perderemos também./ Eis por que a salvação do Universo é também a nossa própria salvação. Por sua vez, a solidariedade entre os homens não é um luxo de corações ternos mas uma profunda necessidade de autoconservação. Uma necessidade como, num exército em combate, a salvação do companheiro de fileira. (KAZANTZAKIS, 1997, p.130-131)

A utilização de um vocabulário bélico indica a inserção de Kazantzakis em seu tempo, consciente de que a "época histórica é um momento de crise violenta [pois] um mundo desaba e o outro ainda não nasceu. (...) não é uma época de equilíbrio, em que a cortesia, a concórdia, a paz e o amor possam ser virtudes fecundas." (KAZANTZAKIS, 1997, p.129) Porém, mais do que uma necessidade de irmanação para o enfrentamento da crise, a interdependência é inerente à própria natureza, concepção que Kazantzakis incorpora do Budismo e mesmo da evolução criadora de Bergson. Homens de todas as raças, animais, vegetais e toda a Terra fazem parte do mesmo círculo de ascensão, os mais rudimentares servindo de base para a elevação das espécies mais sofisticadas, como elementos imorredouros, eternamente permanentes na vida que não cessa ${ }^{10}$. Não seria, portanto, difícil estabelecer a conexão com o leitor, convocado ao círculo de ação para a redenção coletiva por meio da interlocução imperativa e do uso da segunda pessoa do plural, permanentemente presentes e atuantes em Ascese. 
Essa obra constitui-se num texto híbrido, situado entre o literário, o filosófico e o religioso, no qual o herói/leitor é incitado a realizar sua ascese em direção à afirmação dionisíaca da vida, o que consegue realizar por meio da superação do antagonismo entre as diferentes instâncias do humano e da existência. Ascese se propõe como texto transformador e de transformação na medida em que clama à ação, não somente uma ação prática, mas a práxis libertadora de uma escrita que crie condições de diálogo entre os acontecimentos históricos e a força que os gerou e gerará permanentemente. Ascese tem sido valorada como o esqueleto e o coração de toda a obra de Kazantzakis, assim como a trajetória abstrata que será concretizada por Odisseu no texto épico. Como "transposição poética da Odisséia" (IZZET, 1959, p. 7) e ossatura da produção kazantzakiana, Ascese condensa, portanto, o sistema filosófico de Kazantzakis que servirá de base para a composição das obras ulteriores.

A exortação ao leitor para o combate conjunto, seja ela substanciada pelo projeto ético de Kazantzakis ou pela visada filosófica, instaura a interlocução que pode ser avaliada como a relação de discípulo e mestre, pelo tom imperativo característico de Ascese e pela natureza de seu conteúdo, muito próximo aos manuais de exercícios espirituais, aos versículos bíblicos ou mesmo ao Bhagavad Gitá. Embora Ascese não se constitua em um manual, pois vai desconstruindo em sua trajetória a ideia de mestres que sinalizem caminhos, conduzindo o leitor às suas próprias avaliações e à autonomia de escolhas, a proximidade declarada com o leitor provavelmente terá estimulado a identificação do autor com a elocução de mestre exortador no entrecho de Ascese.

A literatura entendida como dever e redenção, pelo movimento duplo de superação individual e exortação da prática do leitor, torna-se compromissada com a ação e com o momento histórico, unindo-se, dessa forma, à intencionalidade do autor e à sua subjetividade. $\mathrm{O}$ autor torna-se inseparável de seu texto, por fazer dele um instrumento de ação e de autotransformação. É provável, portanto, que a relação estabelecida por Kazantzakis com seu texto tenha levado a crítica a voltar-se continuamente para a trajetória pessoal do autor, não como um modo de "melhor" avaliar sua obra, mas certamente por um impulso de admiração e encantamento pela aura que o entorna, como insetos atraídos à luz.

Assim, torna-se mais proveitoso compreender o projeto literário do autor no intuito não de exaltar as peculiaridades de Kazantzakis e de validar suas intenções, mas de entender como relances não previstos do projeto e da trajetória pessoal se apresentam na obra, para além do que o autor supunha ter realizado, favorecendo assim uma leitura que estabeleça a relação - nem sempre harmônica - entre os elementos canônicos do texto e as tensões instauradas por sua significação. 
${ }^{1}$ Peter Bien (2007, p. 4) explica que até nos dias atuais Kazantzakis é considerado pelos jovens politizados gregos um egotista, devotado à própria salvação e, portanto, irrelevante para a realidade grega. É importante ressaltar, no entanto, que Bien procurará desmitificar esta visão simplista e inapropriada.

${ }^{2}$ Grande parte das cartas foi publicada por Eleni Kazantzakis em Kazantzaki. El disidente. (1974). Tratase de uma reunião de cartas comentadas pela autora, que se propõe a elucidar a personalidade do autor e sua trajetória literária. No prólogo, Eleni explica que a obra atende a um pedido de Kazantzakis, para quem a esposa seria a única a conhecê-lo bem, ao contrário de todos os críticos que diriam apenas coisas inexatas.

${ }^{3}$ As expressões marcadas em itálico são nossas para enfatizar o desenvolvimento de nosso argumento.

${ }^{4} \mathrm{Na}$ introdução a esta obra, Eleni adverte que seu conteúdo "é uma mistura de fato e ficção - uma boa parte de verdade, um mínimo de fantasia. Algumas datas foram modificadas. Quando menciona outras pessoas, é sempre com verdade, sem modificações. Exatamente o que viu e ouviu. Quando fala de suas aventuras pessoais, existem algumas pequenas modificações. Mas, uma coisa é certa: se tivesse sido capaz de reescrever este livro, o teria mudado. Exatamente como, não o podemos saber. Certamente o teria enriquecido, já que a cada dia recordava-se de novos acontecimentos que esquecera. E, também, o teria amoldado - acredito eu - à realidade. Sua vida real foi cheia de significado, de vivências dolorosas. De alegria e dor - e para usar uma única palavra, de "dignidade". Por que haveria de ter mudado sua vida? Não por falta de momentos difíceis, de fraquezas, de fugas e de sofrimentos. Ao contrário. Eram exatamente estes momentos que sempre serviram a Kazantzakis como novos degraus que lhe permitiam ascender mais alto. De ascender e alcançar o topo que se tinha prometido a si mesmo escalar antes de abandonar os instrumentos de trabalho porque a noite principiara sua descida". (s/d, p.9)

${ }_{5}^{5}$ As personalidades que Kazantzakis admirou se inserem numa cadeia extensa, outras tantas podem ser mencionadas: Moisés, Dom Quixote, Alexandre Magno, El Greco, Gengis Kan, Dante, Santa Teresa, Cristóvão Colombo. À grande parte desses nomes, o autor dedicou poemas que compõem a obra Tercinas (póstuma, 1960).

${ }^{6}$ As tragédias são: Odisseu, Juliano, o apóstata, Constantino Paleólogo, Héracles, Cristóvão Colombo, Cristo, Buda, Kapodistria, Teseu, Prometeu acorrentado.

${ }^{7}$ Os romances, com suas respectivas figuras solares: Zorba, o grego (o próprio homônimo, representante da tendência dionisíaca e vitalista), A Última Tentação (Cristo), O Cristo Recrucificado (Cristo).

${ }^{8} \mathrm{O}$ caráter de pensador fica bem marcado na obra de Roberto Quiroz Pizarro, Nikos Kazantzakis. Dimensiones de un poeta-pensador, como manifesto já no título, revelando a proposta de abordagem da obra kazantzakiana confundida com a experiência pessoal do autor. Vale, entretanto, notar que o trabalho de Pizarro é a dissertação de mestrado apresentada para a obtenção de grau de mestre em filosofia, o que fornece outra conotação aos seus objetivos, muito embora não minimize o tratamento reverencioso e exaltador conferido a Kazantzakis.

9 A tensão se manifesta claramente na obra Zorba, o grego: o protagonista (narrador-personagem), escritor e intelectual, se mostra angustiado por não ter o mesmo impulso à ação que Zorba, personagem que representa o pólo oposto.

${ }_{10}$ "Teus mortos não jazem sob a terra. Tornaram-se aves, árvores, ventos. Tu te sentas à sombra deles, te nutres da sua carne, respiras o hálito deles. Fizeram-se idéias e paixões que determinam a tua vontade e as tuas ações. As futuras gerações não se agitam num tempo incerto, distante de ti. Vivem, atuam e desejam nos teus rins e no teu coração". (KZANTZAKIS, 1997, p. 70-71) 
Referências Bibliográficas:

BAUDIER, Marie-Louise Bidal. Nikos Kazantzakis. Cómo el hombre se hace inmortal. Buenos Aires: Ediciones Carlos Lohlé, 1987.

BIEN, Peter. Kazantzakis. Polites of the Spirit. Volume 1. New Jersey: Princeton University Press, 2007.

FOUCAULT, Michel. O que é um autor? Lisboa: Editora Vega, 1992.

IZZET, Aziz. "Introduction" In: KAZANTZAKIS, N (org.). Ascèse Salvatores Dei. Paris: Librairie Plon, 1959.

KAZANTZAKIS. Ascese Os Salvadores de Deus. Tradução José Paulo Paes. São Paulo: Ática, 1997.

- Testamento para El Greco. Tradução Clarice Lispector. Rio de Janeiro:

Artenova, s/d.

KAZANTZAKI, Eleni. Kazantzaki. EI disidente. Visto a través de sus cartas, sus notas, sus textos inéditos. Barcelona: Editorial Planeta, 1974.

MACHADO, Roberto. O Nascimento do Trágico. De Schiller a Nietzsche. Rio de Janeiro: Jorge Zahar Editor, 2006.

NUNES, Benedito. “A Visão Romântica”. In: GUINSBURG, J (org.). O Romantismo. São Paulo: Perspectiva, 1993.

PIZARRO, Roberto Quiroz. Nikos Kazantzakis. Dimensiones de un poeta-pensador. Santiago, Universidad de Chile, 2003. 